\title{
PENGARUH TEMPERATUR DAN WAKTU HOMOGENISASI TERHADAP KARAKTERISTIK PELAT PADUAN AG3NE
}

\author{
Hadijaya, Siti Aidah,Masrukan \\ Pusat Teknologi Bahan Bakar Nuklir - BATAN \\ Kawasan Puspiptek Serpong Gd.20 Tangerang Selatan, Banten 15314 \\ e-mail: galihway@batan.go.id
}

(Naskah diterima: 01-06-2018, Naskah direvisi: 10-06-2018, Naskah disetujui: 30-06-2018)

\begin{abstract}
ABSTRAK
PENGARUH TEMPERATUR DAN WAKTU HOMOGENISASI TERHADAP KARAKTERISTIK PELAT PADUAN AG3NE. Telah dilakukan penelitian mengenai pengaruh temperatur dan waktu homogenisasi terhadap karakteristik pelat paduan AG3NE. Paduan AG3NE merupakan paduan yang dapat digunakan sebagai kelongsong elemen bakar reaktor riset. Ingot hasil peleburan AlMgFeSi dicuplik untuk dilakukan beberapa pengujian diantaranya komposisi kimia, kekerasan, mikrostruktur, fasa, densitas dan korosi. Hasil pengujian komposisi kimia dipoeroleh unsur $\mathrm{Al}=96,110 \% ; \mathrm{Fe}=0,188 \% ; \mathrm{Mg}=2,333$ dan $\mathrm{Si}=0,355 \%$. Kekerasan $\mathrm{AG} 3 \mathrm{NE}$ yang dikenai proses pendinginan cepat diperoleh sebesar $153,33 \mathrm{HV}$; sedangkan yang mengalami pendinginan lambat 72,70 HV, dan kekerasan paduan AIMgSi sebesar 79,30 HV. Hasil analisis mikrostruktur menggunakan mikroskop optik menunjukkan bahwa paduan AG3NE tanpa dihomogenisasi mempunyai bentuk butir pipih sebagian berbentuk dendrite dengan diameter butir rata-rata 0,02 $\mathrm{mm}$ sedangkan paduan AG3NE yang dihomogenisasi pada temperatur $500^{\circ} \mathrm{C}$ dengan variasi waktu selama $1 ; 2 ; 3$ dan 4 jam mempunyai butir dengan diameter rata-rata berturut-turut sebesar $0,01 \mathrm{~mm}, 0,02 \mathrm{~mm}, 0,03 \mathrm{~mm}$ dan $0,04 \mathrm{~mm}$. Hasil uji fasa menggunakan XRD diperoleh fasa $\mathrm{Al}$ (á) dan fasa kedua $\mathrm{FeSiAl}_{5}$ yang terdapat pada sudut $2 \theta$ sebesar $38,24^{\circ}$ dan $44,446^{\circ}$ dengan hkl masing-masing (119) dan (209) serta mempunyai intensitas sinar sebesar $100 \%$ dan $76,6 \%$. Sementara itu dari hasil pengukuran densitas AG3NE diperoleh densitas rerata yang hampir sama dengan paduan AIMgSi sebagai pembanding. Densitas paduan AG3NE diperoleh sebesar 2,6893 $\pm 0,0013 \mathrm{~g} / \mathrm{cm}^{3}$, sedangkan AIMgSi sebesar 2,6910 $\pm 0,0283 \mathrm{~g} / \mathrm{cm}^{3}$. Sementara itu, hasil uji korosi menunjukkan bahwa laju korosi paduan AG3NE lebih rendah dibandingkan dengan paduan AIMgSi. Hasil karakterisasi komposisi kimia, kekerasan mikro, mikrostruktur, densitas dan laju korosi dapat disimpulkan bahwa paduan AG3NE dapat digunakan sebagai kandidat kelongsong bahan bakar nuklir untuk reaktor riset.
\end{abstract}

Kata kunci: Paduan AG3NE, AIMgSi, homogenisasi, karakterisasi, bahan struktur. 


\section{ABSTRACT}

EFFECTS OF HOMOGENIZATION TEMPERATURE AND TIME ON THE CHARACTERISTICS OF AG3NE ALLOY PLATE. Investigation on the effects of homogenization temperature and time on AG3NE alloy plate has been done. AG3NE alloy is used as cladding material of research reactor fuel. Ingot of AIMgFeSi melt was sampled for several tests and examination such as chemical composition, hardness, microstructure, phase, density and corrossion. Composition analysis shows that the alloy is composed of $A l=96.110 \%, F e=0.188 \%, M g=2.333 \%$ and $\mathrm{Si}=0.355 \%$. The hardness value for AG3NE is $153.33 \mathrm{HV}$ for samples treated with rapid cooling and $72.70 \mathrm{HV}$ for samples treated with slow cooling. Microstructure examination with optical microscope shows that $A G 3 N E$ alloy without homogenization consists of flat grains with a fraction of dendrite of $0.02 \mathrm{~mm}$ mean diameter, while samples homogenized at $500^{\circ} \mathrm{C}$ at varied temperatures of 1, 2, 3, and 4 hours consist of grains with $0.01 \mathrm{~mm}, 0.02 \mathrm{~mm}, 0.03 \mathrm{~mm}$ and $0.04 \mathrm{~mm}$ respectively.Phase analysis with X-Ray Difractometer indicates the existance of Al (ó) and $\mathrm{FeSiAl}_{5}$ phases at $2 \theta$ of $38.24^{\circ}-\mathrm{hkl}(119)$ and $44.446^{\circ}-h \mathrm{kl}(209)$ with $100 \%$ and $76.6 \%$ intensity respectively. The measured density of AG3NE, however, is similar to that of AIMgSi as material for comparison, the values of which are $2.6893 \pm 0.0013 \mathrm{~g} / \mathrm{cm}^{3}$ for AG3NE and $2.6910 \pm 0.0283 \mathrm{~g} / \mathrm{cm}^{3}$ for AIMgSi. Corrossion rate analysis shows that the corrossion rate for AG3NE is lower than that for AIMgSi. Based on the characterization for chemical composition, microhardness, microstructure, density and corrossion rate, it is concluded that AG3NE alloy can be used as a candidate for cladding material for research reactor fuel.

Keywords: AG3NE, AIMgSi, homogenization, characterization, structural material. 


\section{PENDAHULUAN}

Bahan bakar yang digunakan pertama kali untuk pengoperasian reaktor RSG-GAS adalah jenis $\mathrm{U}_{3} \mathrm{O}_{8} / \mathrm{Al}$ kemudian diganti dengan jenis $\mathrm{U}_{3} \mathrm{Si}_{2} / \mathrm{Al}$ karena mempunyai densitas lebih tinggi dari pada $\mathrm{U}_{3} \mathrm{O}_{8} / \mathrm{Al} \quad\left(8,41 \mathrm{gU} / \mathrm{cm}^{3}\right)$. Kelongsong yang digunakan sebagai pembungkus bahan bakartersebut adalah paduan AIMg2.Upaya untuk mendapatkan karakter kelongsong yang kompatibel dengan $\mathrm{U}_{3} \mathrm{Si}_{2} / \mathrm{Al}$ sebagai bahan bakar perlu dikembangkan kelongsong yang sesuai dengan bahan bakar yang digunakan. Pengembangan kelongsong diarahkan dari paduan AlMg2 menjadi paduan AlMgFeSi dengan pertimbangan bahwa paduan AIMgFeSi mempunyai ketahanan korosi dan kekerasan lebih baik dibandingkan paduan AlMg2 yang saat ini digunakan[1]. Paduan AlMgFeSi atau dikenal sebagai AG3NE merupakan alternatif bahan struktur yang dapat digunakan sebagai kelongsong. Pemanfaatan paduan AG3NE sebagai kelongsong hampir sama dengan penggunaan kelongsong AIMg2 maupun AIMgSi.

Dalam pengembangan penggunaan paduan AIMgFeSi sebagai kelongsong bahan bakar nuklir perlu diketahui sifat ketahanan korosi, kekerasan,mekanik, fisik maupun termal dari paduan tersebut[2]. Oleh sebab itu dalam mendesain suatu paduan menjadi kelongsong bahan bakar perlu dipertimbangkan jenis unsur yang akan ditambahkan. Di dalam paduan aluminium unsur-unsur yang penting ditambahkan untuk memperbaiki sifat mekaniknya antaralainadalah unsur $\mathrm{Mg}, \mathrm{Si}$, dan $\mathrm{Fe}$. Unsur $\mathrm{Mg}$ didalam paduan aluminium memperbaiki kekuatan dan keuletan hasil pengerjaan dingin, bahkan dapat memperbaiki ketahanan terhadap korosi dan mampu las. Unsur $\mathrm{Fe}$ akan mempertahankan butir pada temperatur tinggi karena terbentuknya fasa kedua. Pengerasan dispersi merupakan pengerasan melalui proses memasukkan partikel-partikel dispersi dalam bentuk serbuk yang tercampur secara homogen. Partikel dispersi merupakan partikel yang tidak larut dalam matriknya. Partikel dispersi menjadi penghalang bagi gerakan dislokasi. Dislokasi semakin banyak mengakibatkan celah semakin rapat sehingga bahan akan menjadi keras. Orientasi setiap butir berbeda dengan yang lain, sehingga orientasi bidang slip pada butir-butir juga akan berbeda-beda. Oleh sebab itu pergerakan dislokasi akan terhambat. Gerakan dislokasi yang melintasi batas butir membutuhkan tegangan yang lebih besar sehingga batas butir menjadi penghalang dan menghambat gerakan dislokasi. Penguatan tekstur merupakan peningkatan kekuatan atau kekerasan melalui orientasi kristal. Jika logam paduan ingin ditingkatkan kekuatannya maka kristalnya harus memiliki orientasi tertentu. Terbentuknya fasa kedua akan memperlambat proses rekristalisasi sehingga mencegah butir tidak semakin membesar dan akhirnya menurunkan kekuatan paduan.

Sementara itu, temperatur lebur suatu bahan akan menentukan mudah tidaknya bahan tersebut melebur bila terkena panas. Aluminium dengan kemurnian tinggi mempunyai temperatur lebur lebih tinggi dibandingkan yang kemurniannya lebih rendah. Demikian pula dibandingkan dalam bentuk paduan, titik lebur paduan menurun sejalan dengan naiknya kandungan unsur pemadunya sampai mencapai titik eutektiknya. Penggunaan untuk bahan kelongsong bahan bakar diharapkan mempunyai titik lebur yang tinggi agar selama digunakan di reaktor tidak mudah meleleh. Logam aluminium mempunyai titik lebur relatif sekitar $660^{\circ} \mathrm{C}$ masih memungkinkan karena reaktor riset beroperasi pada temperatur yang relatif rendah yakni sekitar $120^{\circ} \mathrm{C}$.

Panas jenis adalah banyaknya panas yang dibutuhkan untuk menaikkan temperatur tiap gram tiap derajat Celsius 
atau Kelvin. Bahan kelongsong diharapkan mempunyai harga panas jenis rendah agar secara cepat dapat memindahkan panas ke sekeliling[3]. Panas jenis (Cp) merupakan sifat termal yang juga berperan penting dalam operasi metalurgi pengecoran atau perlakuan panas karena menentukan jumlah panas yang dibutuhkan dalam proses. Hal ini berarti panas jenis mengendalikan kenaikan temperatur yang disebabkan penambahan sejumlah panas terhadap setiap gram logam[4]. Ketika logam dipasok dengan energi panas, sebagian panas akan diserap oleh kisi untuk menaikkan amplitudo getaran ion, tetapi sebagian kecil akan diserap oleh elektron-elektron pada puncak lingkaran energi.

Paduan AG3NE merupakan paduan aluminium dalam kelompok seri 6xxx yang dapat digunakan untuk bahan struktur, bahan konstruksi, automotif dan jembatan. Logam paduan AG3NE mempunyai komposisi unsur utama sama dengan paduan AIMg2 atau AlMgSi yaitu Al dan sejumlah unsur pemadu seperti $\mathrm{Fe}, \mathrm{Mg}$ dan Si yang berfungsi untuk mengendalikan sifat mekanik paduan tersebut. Paduan aluminium secara umum dipilih untuk kelongsong bahan bakar disebabkan antara lain sifatnya yang ringan, ketahanan korosi baik, konduktivitas panas baik, mudah difabrikasi dan kekerasan mendekati kekerasan bahan bakar[5]. Selain itu, paduan aluminium dengan kandungan unsur pemadunya mempunyai sifat fisik, mekanik, termal dan neutronik yang baik untuk kelongsong bahan bakar.

Di dalam reaktor, kelongsong bahan bakar akan menjadi panas karena terjadi reaksi fisi antara bahan bakar $\mathrm{U}_{3} \mathrm{Si}_{2} / \mathrm{Al}$ dengan neutron. Panas yang disebabkan oleh reaksi fisi tersebut harus segera dipindahkan ke air pendingin agar tidak terjadi akumulasi panas yang menyebabkan swelling bahan bakar. Pemindahan panas tersebut sangat dipengaruhi oleh sifat termal dari bahan kelongsong tersebut yakni konduktivitas panasnya dan panas jenisnya[6]. Oleh sebab itu pada penelitian ini dipelajari mengenai pengaruh temperatur dan waktu homogenisasi terhadap karakteristik pelat paduan AG3NE.

\section{METODOLOG}

Bahan baku ingot $\mathrm{Al}$ ditambah unsur pemadu $\mathrm{Mg}$ dan $\mathrm{Si}$ (dalam bentuk $\mathrm{Al}-\mathrm{Si}$ ) dimasukkan ke dalam tungku lebur. Ingot $\mathrm{Al}$ dan $\mathrm{Si}$ dimasukkan terlebih dahulu kemudian setelah kedua unsur tersebut melebur pada $800^{\circ} \mathrm{C}$ dimasukkan $\mathrm{Al}$ dan ditambahkan degasser untuk mengusir gas dan flux untuk menghilangkan kotoran. Hasil peleburan diperoleh ingot AIMgFeSi, kemudian dilakukan pencuplikkan untuk dianalisis komposisi menggunakan alat Spektrometer Serapan Atom (AAS). Apabila dari uji komposisi kimia telah memenuhi persyaratan kelongsong bahan bakar reaktor risetmaka dilanjutkandengan proses homogenisasi, namun bila tidak memenuhi persyaratan sebagai kelongsong bahan bakar maka dilakukan peleburan ulang. Penelitian diawali dengan penyediaan bahan base alloy yaitu aluminium granule dan serbuk $\mathrm{Si}, \mathrm{Mg}$, Fe kemudian dilebur pada temperatur $800^{\circ} \mathrm{C}$ selama 120 menit sambil dilakukan pengadukan, kemudian dituang ke dalam cetakan. Setelah itu ketiga masteralloy diremelting bersama base-alloy hingga diperoleh paduan AG3NE. Paduan AG3NE selanjutnya diroll panas pada $500^{\circ} \mathrm{C}$ dan dihomogenisasi dengan melakukan pemanasan pada temperatur 400, 500 dan $600^{\circ} \mathrm{C}$. Paduan hasil pengerolan dikarakterisasi meliputi mikrostruktur (grain size), kekerasan (microhardness), komposisi kimia (OES), fasa (XRD), laju korosi (potensiostat) serta densitas (ultra pycnometer). Hasil karakterisasi paduan AG3NE akan dibandingkan dengan karakteristik paduan AIMgSi yang selama ini digunakan sebagai bahan kelongsong elemen bakar reaktor riset. Secara menyeluruh langkah penelitian dilakukan seperti diagram alir yang ditunjukkan pada Gambar 1. 


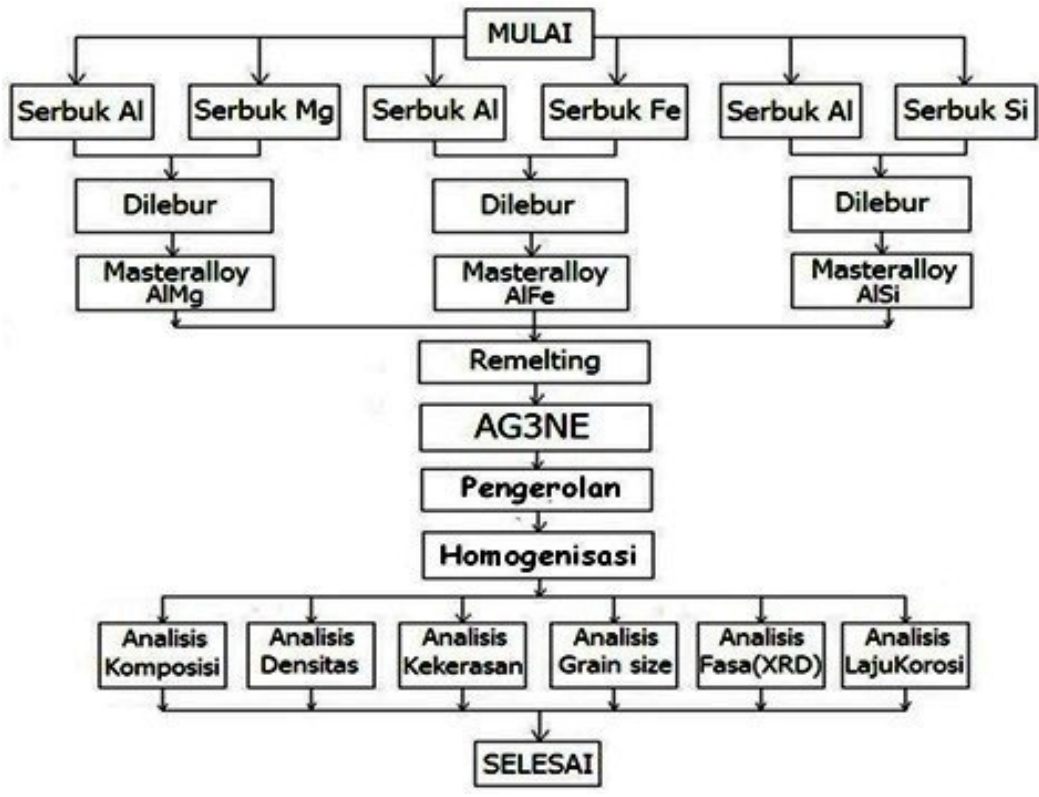

Gambar 1. Diagram alir penelitian pembuatan paduan AG3NE.

\section{HASIL DAN PEMBAHASAN}

\section{a. Analisis komposisi kimia}

Hasil analisis komposisi unsur kimia terhadap paduan AG3NE dan unsur pengotor menggunakan Optical Emission Spektrometer (OES) ditunjukkan pada Tabel 1. Tabel 1 menunjukkan bahwa komposisi unsur yang digunakan dalam pembuatan paduan AG3NE (direncanakan) terdiri dari kandungan unsur $\mathrm{Mg} 2,78 \%, \mathrm{Fe}$ $0,26 \%$, Si $0,15 \%$ dan Al 96,81\%. Berdasarkan hasil pengujian komposisi paduan AG3NE menggunakan emission spektrometer diperoleh hasil yang tidak jauh berbeda. Kandungan $\mathrm{Fe}$ pada awalnya sebesar $0,26 \%$, tetapi dalam paduan AG3NE hanya $0,0081 \%$. Hal ini terjadi kemungkinan karena hilang atau terbuang pada saat proses pengadukan. Sementara itu, kandungan $\mathrm{Mg}$ pada awalnya sebesar $2,78 \%$ namun setelah proses peleburan yang dihasilkan hanya $0,0057 \%$. Hal ini disebabkan karena sifat $\mathrm{Mg}$ yang mudah teroksidasi dan ketika kontak dengan temperatur tinggi pada $800^{\circ} \mathrm{C}$ sangat sedikit yang mengalami ikatan intermetalik dengan unsur aluminium, sedangkan kandungan $\mathrm{Si}$ pada awalnya sebesar $0,15 \%$ dan hasil analisis yang diperoleh sekitar 0,1196\%. Hasil analisis ini tidak mempunyai perbedaan yang signifikan. Sementara itu, adanya unsur pengotor kemungkinan disebabkan karenahasil peleburan AG3NE berkontak langsung dengan cetakan yang terbuat dari batu tahan api, alat pengaduk dan adanya debu dalam chamber pada saat furnace digunakan.

Tabel 1. Komposisi unsur pemadu dalam paduan AG3NE

\begin{tabular}{cccc}
\hline Unsur & $\begin{array}{c}\text { Kandungan awal yang } \\
\text { ditambahkan dalam paduan (\%) }\end{array}$ & $\begin{array}{c}\text { Hasil } \\
\text { analisis (\%) }\end{array}$ & $\begin{array}{c}\text { Persyaratan } \\
\text { kelongsong[5] }\end{array}$ \\
\hline $\mathrm{Al}$ & 96,81 & 96,110 & base \\
$\mathrm{Fe}$ & 0,26 & 0,188 & 0,30 \\
$\mathrm{Mg}$ & 2,78 & 2,333 & $1,7-2,4$ \\
$\mathrm{Si}$ & 0,15 & 0,355 & 0,30 \\
Pengotor & - & 1,014 & - \\
\hline
\end{tabular}




\section{b. Kekerasan mikro}

Hasil analisis kekerasan mikro AG3NE yang dianalisis ditampilkan pada Tabel 2.

Tabel 2. Data kekerasan mikro AG3NE

\begin{tabular}{lc}
\hline \multicolumn{1}{c}{ KodeSampel } & Kekerasan HVN \\
\hline AG-Q & 153,33 \\
AG-A & 72,70 \\
AIMgSi (pembanding) & 79,30 \\
\hline
\end{tabular}

Keterangan :

1. AG-Q adalah sampel AG3NE hasil pendinginan cepat (quenching)

2. AG-A adalah sampel AG3NE hasil pendinginan lambat (aniling)

Tabel 2 menunjukkan bahwa paduan AG3NE setelah mengalami proses peleburan dan dikenai dengan proses pendinginan cepat mempunyai kekerasan yang lebih tinggi dibandingkan dengan paduan AG3NE yang dibuat melalui pendinginan lambat. Paduan AG3NE yang diperoleh melalui pendinginan cepat mempunyai kekerasan 153,33 HV sedangkan paduan AG3NE yang diperoleh melalui pendinginan lambat mempunyai kekerasan 72,22 HV. Sementara itu, kekerasan paduan AIMgSi sebagai sampel pembanding mempunyai kekerasan sebesar 79,30 HV. Perbedaan kekerasan ini disebabkan karena paduan AG3NE yang didinginkan secara cepat menyebabkan terjadi inti-inti yang lebih banyak dan dengan meningkatnya temperatur inti-inti tersebut tumbuh menjadi butir sehingga terbentuk butir yang lebih banyak. Terbentuknya butir yang lebih banyak juga terjadi pertumbuhan butir yang mengarah ke arah pusat pengintian sehingga membentuk butir dengan struktur dendrite. Oleh karena paduan AG3NE yang mengalami pendinginan cepat mempunyai butir yang lebih banyak sehingga kekerasan paduan tersebut menjadi lebih tinggi. Semakin banyak butir yang terbentuk menyebabkan semakin sulit dislokasi bergerak sehingga kekerasan paduan menjadi meningkat. Apabila diamati dari tingkat kekerasannya, paduan AlMgSi yang mempunyai kekerasan sebesar 79,30 HV merupakan paduan yang diperoleh melalui proses peleburan dengan pendinginan lambat. Kekerasan suatu paduan ditentukan oleh unsur pemadu dan perlakuan terhadap paduan tersebut. Unsur pemadu yang ditambahkan membentuk fasa kedua atau presipitat sedangkan perlakuan (panas, mekanik atau termomekanik) akan menentukan besar butir yang terbentuk pada paduan tersebut. Semakin banyak fasa dan butir yang terbentuk semakin keras paduan logam yang terjadi, demikian sebaliknya[7].

Hasil kekerasan mikro paduan AG3NE setelah mengalami perlakukan panas yaitu dihomogenisasi pada temperature $500^{\circ} \mathrm{C}$ dan dirol pada tingkat reduksi yang bervariasi ditampilkan pada Gambar 2.

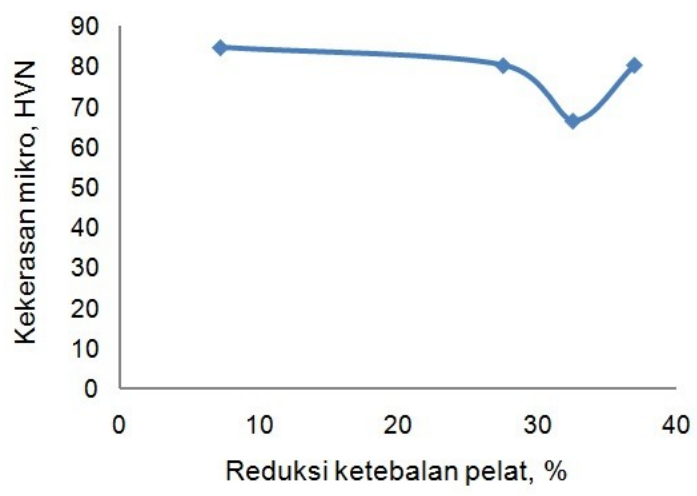

Gambar 2. Kekerasan mikro pelat AG3NE hasil dihomogenisasi pada $500^{\circ} \mathrm{C}$

Gambar 2 menunjukkan bahwa pada reduksi pengerolan yang semakin besar tidakmenyebabkan perubahan kekerasan paduan AG3NE secara signifikan. Pada pengerolan dengan reduksi sebesar $7,22 \%$ paduan AG3NE mempunyai kekerasan sebesar 84,73 HV kemudian setelah dirol dengan tingkat reduksi sebesar 36,97\% paduan AG3NE mempunyai kekerasan sebeasr 80,4 HV. Hal ini menunjukkan bahwa deformasi yang diberikan pada paduan AG3NE pada proses pengerolan 
panas meskipun semakin tinggi ternyata tidak mempengaruhi tingkat kekerasannya. Keadaan ini disebabkan karena aluminium merupakan logam yang mempunyai energi salah tumpuk/stacking false energy (SFE) tinggi, sehingga deformasi pada temperatur tinggi tidak banyak memberi pengaruh.

Sementara itu, hasil pengamatan kekerasan mikro paduan AG3NE yang dihomogenisasi pada temperatur $400^{\circ} \mathrm{C}$, $500^{\circ} \mathrm{C}$ dan $600^{\circ} \mathrm{C}$ ditunjukkan pada Gambar 3.

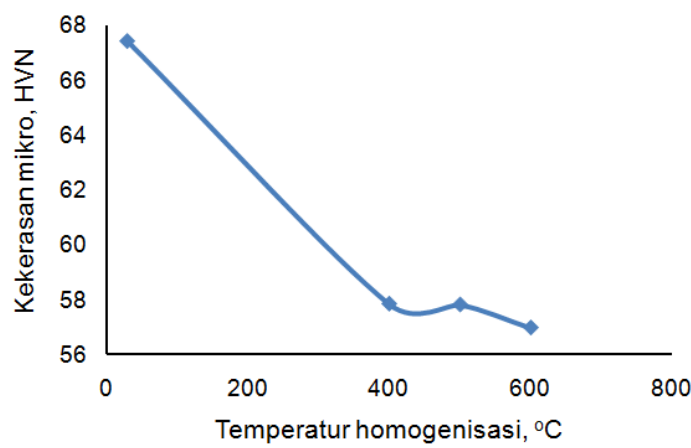

Gambar 3. Kekerasan mikro AG3NE variasi temperatur homogenisasi.

Gambar 3 menunjukkan bahwa bahwa pada temperatur homogenisasi yang semakin tinggi diperoleh kekerasan mikro paduan AG3NE semakin rendah. Apabila dibandingkan dengan sampel AG3NE tanpa proses homogenisasi dapat diketahui bahwa paduan AG3NE yang dihomogenisasi mempunyai kekerasan mikro lebih rendah. Hal ini disebabkan paduan AG3NE yang dihomogenisasi telah mengalami perbesaran butir akibat dari proses homogenisasi tersebut. Apabila ukuran butir suatu paduan logam semakin besar maka dislokasi yang ada akan semakin mudah bergerak sehingga kekerasan paduan logam menjadi semakin rendah.

\section{c. Analisis mikrostruktur}

Hasil analisis mikrostruktur paduan AG3NE menggunakan mikroskop optik yang dilengkapi dengan software untuk menghitung butir ditampilkan pada Gambar 4 hingga 9. Hasil analisis menunjukkan bahwa paduan AG3NE tanpa dihomogenisasi mempunyai bentuk butir pipih sebagian berbentuk dendrite dengan diameter butir rata-rata 0,02 $\mathrm{mm}$, sedangkan untuk paduan AG3NE yang dihomogenisasi pada temperatur $500^{\circ} \mathrm{C}$ dengan variasi waktu selama 1 jam, 2 jam, 3 jam dan 4 jam mempunyai butir yang semakin besar dengan diameter rata-rata berturut-turut sebesar 0,01 mm, 0,02 mm, 0,03 mm dan $0,04 \mathrm{~mm}$. Ukuran diameter butir paduan AG3NE dan paduan AIMgSi sebagai pembanding ditampilkan pada Tabel 3 .

Tabel 3. Diameter butir paduan AG3NE setelah dihomogenisasi

\begin{tabular}{cll}
\hline No. & \multicolumn{1}{c}{ Kode sampel } & $\begin{array}{l}\mathrm{d}_{\text {rerata }} \\
(\mathrm{mm})\end{array}$ \\
\hline 1. & AIMgSi & 0,010 \\
2. & AG3NE tanpa perlakuan & 0,010 \\
3. & AG3NE- 1 jam & 0,010 \\
4. & AG3NE- 2 jam & 0,020 \\
5. & AG3NE- 3 jam & 0,030 \\
6. & AG3NE- 4 jam & 0,040 \\
\hline
\end{tabular}

Sementara itu, paduan AIMgSi yang digunakan sebagai pembanding mempunyai bentuk butir pipih dengan diameter rata-rata sebesar 0,01 $\mathrm{mm}$ seperti yang ditunjukkan pada Gambar 4.

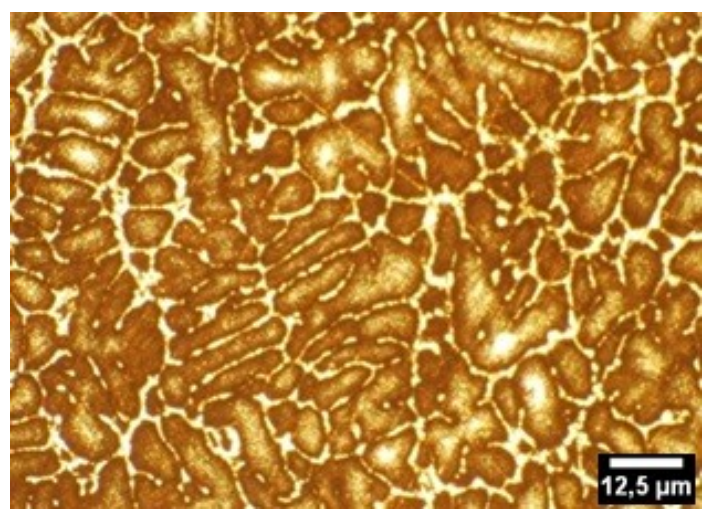

Gambar 4. Paduan AIMgSi pembanding dengan diameter rata-rata 0,01 $\mathrm{mm}$.

Paduan AG3NE yang dihomogenisasi pada temperature $500^{\circ} \mathrm{C}$ terjadi perubahan bentuk butir yang semula pipih menjadi melebar seperti yang terlihat pada Gambar 5 . 
Gambar 5 dan 6 merupakan paduan AG3NE tanpa dihomogenisasi dan dihomogenisasi pada temperature $500^{\circ} \mathrm{C}$ selama $1 \mathrm{jam}$ mempunyai bentuk butir yang hampir sama dan diameter rata-rata yang sama pula yaitu sebesar $0,01 \mathrm{~mm}$. Hal ini berarti bahwa proses homogenisasi selama 1 jam belum mampu mengubah besar dan bentuk butir secara signifikan.

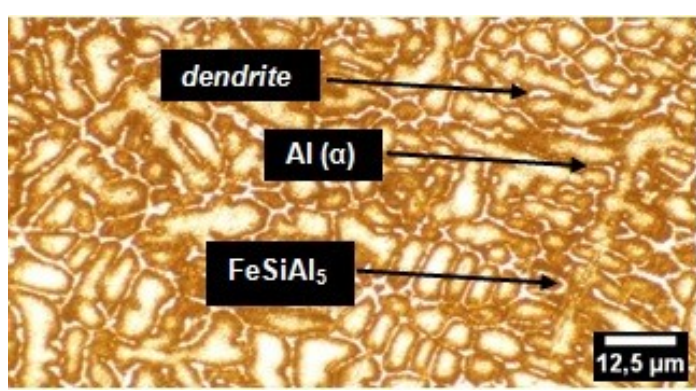

\section{Gambar 5. Paduan AG3NE tanpa homogenisasi dengan diameter butir rata-rata $0,010 \mathrm{~mm}$.}

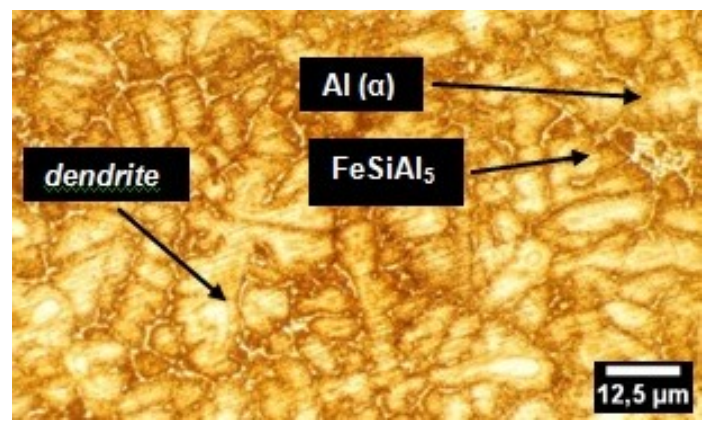

Gambar 6. Paduan AG3NE dihomogenisasi pada $500^{\circ} \mathrm{C}$ selama 1 jam dengan diameter butir rata-rata sebesar $0,010 \mathrm{~mm}$.

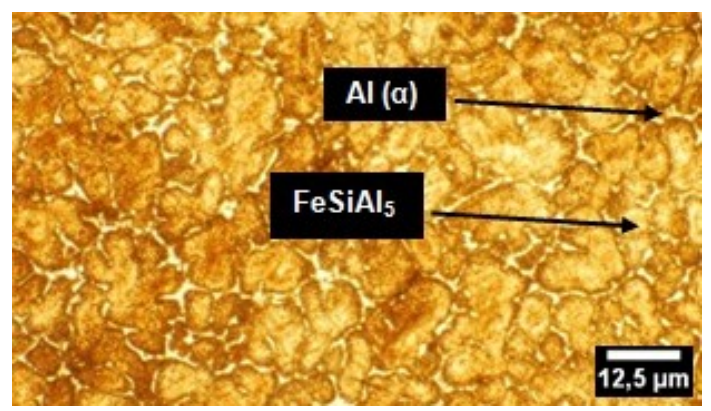

Gambar 7. Paduan AG3NE dihomogenisasi $500^{\circ} \mathrm{C}$ selama 2 jam dengan diameter butir rata-rata sebesar $0,020 \mathrm{~mm}$.

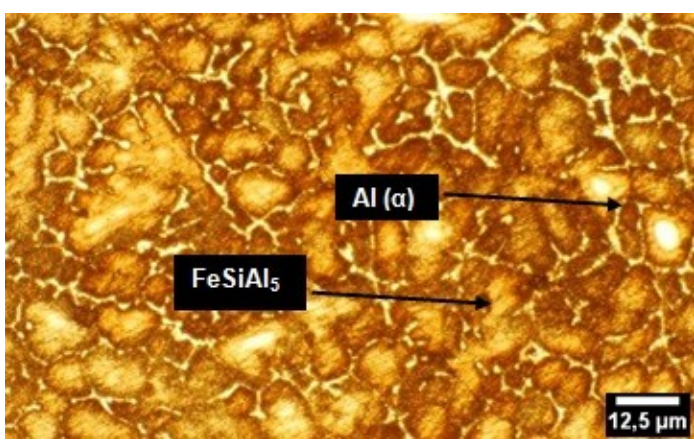

Gambar 8. Paduan AG3NE dihomogenisasi $500^{\circ} \mathrm{C}$ selama 3 jam dengandiameter butir rata-rata $0,030 \mathrm{~mm}$.

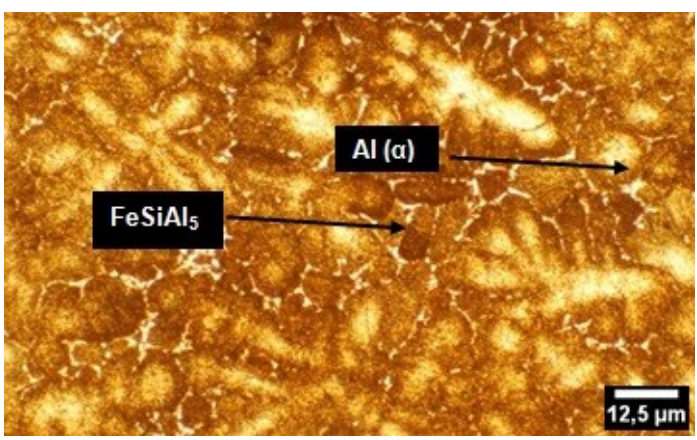

Gambar 9. Paduan AG3NE dihomogenisasi $500^{\circ} \mathrm{C}$ selama 4 jam dengan diameter butir rata-rata sebesar $0,040 \mathrm{~mm}$

Gambar 7 hingga 9 memperlihatkan paduan AG3NE yang dihomogenisasi berturut-turut selama 2 jam, 3 jam dan 4 jam mengalami perubahan bentuk dan ukuran butir. Semakin lama waktu homogenisasi menghasilkan bentuk butir yang semakin bulat dan semakin besar. Hal ini disebabkan proses homogenisasi pada temperatur $500^{\circ} \mathrm{C}$ dengan waktu yang semakin lama meningkatkan jumlah panas yang diberikan kepada paduan dan mengubah bentuk butir yang semula pipih menjadi bulat dan antar butir saling bertemu sehingga menghasilkan butir yang semakin besar. Apabila dibandingkan dengan butir pada paduan AlMgSi terlihat bahwa paduan AlMgSi mempunyai bentuk butir pipih dengan ukuran butir 0,001 mm. Hal ini berarti paduan AIMgSi merupakan paduan yang diperoleh dari peleburan yang telah dirol 
tanpa dihomogenisasi. Selain itu, dari analisis mikrostruktur diperoleh fasa yang terbentuk pada paduan AG3NE terdiri dari unsur $\mathrm{Al}, \mathrm{Mg}$, $\mathrm{Fe}$ dan Si. Dengan memperhatikan hasil uji XRD dan diagram fasa quartener Al-Mg-Fe-Si dapat diperkirakan paduan AG3NE tersebut terdiri dari dua fasa yaitu fasa Al (ó) sebagai matriks dan fasa kedua $\mathrm{FeSiAl}_{5}[8]$. Sementara itu, paduan AIMgSi yang terdiri dari unsur $\mathrm{Al}, \mathrm{Mg}$ dan Si terdiri dari fasa $\mathrm{Al}$ (á) sebagai matriks dan fasa kedua $\mathrm{Mg}_{2} \mathrm{Si}$, dimana fasa-fasa di dalam paduan AIMgSi tersebut bersesuaian dengan diagram fasa quasi binary $\mathrm{Al}-\mathrm{Mg}_{2} \mathrm{Si}[9]$.

\section{d. Analisis fasa}

Hasil pengujian fasa menggunakan teknik difraksi sinar-X (XRD) dengan metode kontinyu dan sudut pengukuran pada rentang 20-80 derajat, beda potensial $40 \mathrm{kV}$ dan kuat arus $30 \mathrm{~mA}$ ditampilkan pada
Gambar 10. Gambar 10 menunjukkanfasa Al (á) yang muncul pada sudut $2 \theta$ berturutturut sebesar $38,24^{\circ} ; 44,446^{\circ} ; 64,7335^{\circ}$ dan $77,8086^{\circ}$ dengan hkl masing-masing adalah (111), (200), (220) dan (311) serta intensitas sinar masing-masing sebesar $100 \%, 76,6 \%$, $20,35 \%$ dan 23,62 \%. Fasa Al (á) merupakan fasa yang terbentuk karena adanya unsur-unsur pemadu $\mathrm{Fe}$, Si dan $\mathrm{Mg}$ yang larut padat. Tidak terdeteksi adanya fasa kedua yang mengandung $\mathrm{Mg}$ bisa disebabkan oleh karena unsur Mg mudah menguap karena titik leburnya rendah sehingga pada saat peleburan, unsur Mg banyak yang telah menguap sehingga tidak membentuk fasa kedua tetapi sebagian larut padat. Selain fasa Al (á), fasa kedua yang muncul adalah $\mathrm{FeSiAl}_{5}$ yang terdapat pada sudut $2 \theta$ sebesar $38,24^{\circ}$ dan $44,446^{\circ}$ dengan hkl masing-masing (119) dan (209) serta mempunyai intensitas sinar sebesar $100 \%$ dan $76,6 \%[10]$.

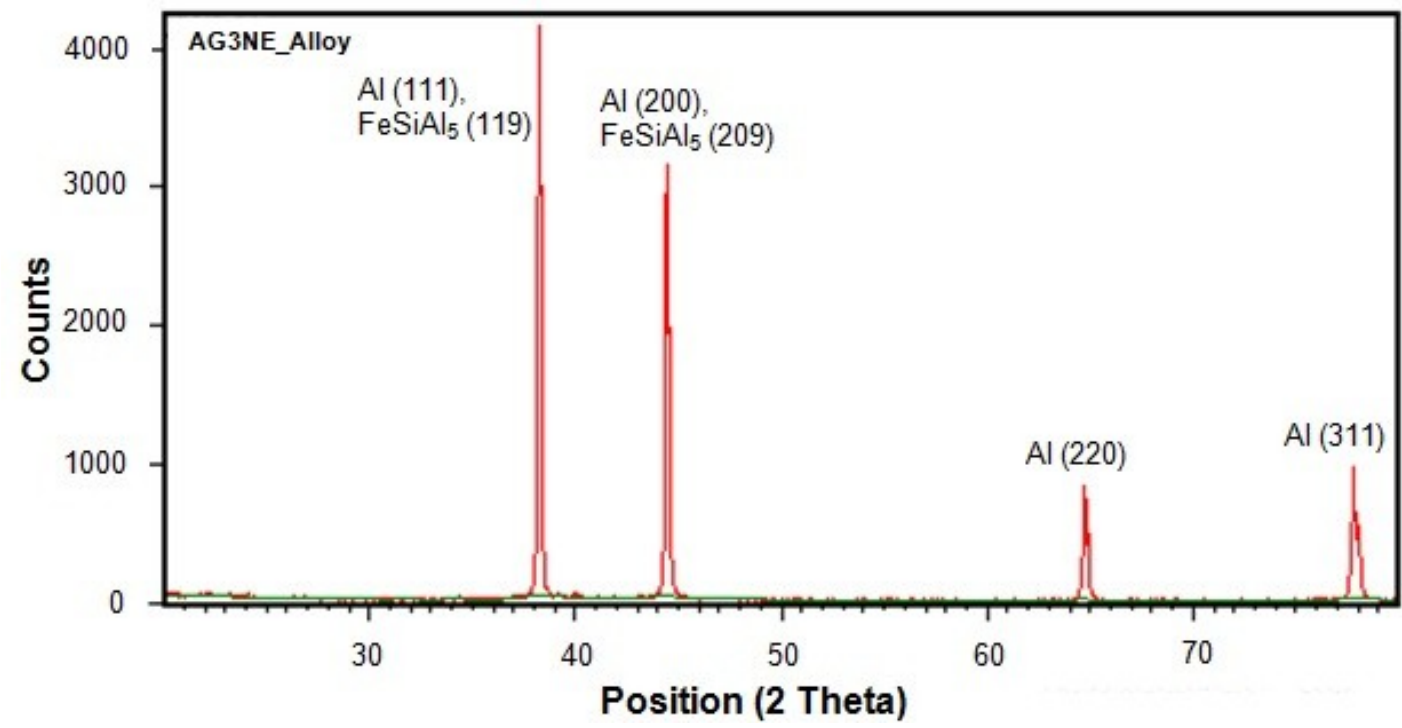

Gambar 10. Pola difraksi sinar-X paduan AG3NE

\section{e. Densitas}

Hasil pengukuran densitas paduan AG3NE ditampilkan pada Tabel 4. Tabel 4 menunjukkan bahwa paduan AG3NE hasil peleburan mempunyai densitas rerata yang hampir sama dengan paduan AIMgSi sebagai pembanding. Densitas paduan AG3NE diperoleh sebesar 2,6893 $\pm 0,0013$ $\mathrm{g} / \mathrm{cm}^{3}$, sedangkan AIMgSi 2,6910 $\pm 0,0283$ $\mathrm{g} / \mathrm{cm}^{3}$. Hal ini menunjukkan bahwa penambahan unsur pemadu $\mathrm{Mg}$, Fe dan $\mathrm{Si}$ dalam paduan AG3NE maupun unsur $\mathrm{Mg}$ dan Si di dalam paduan AIMgSi tidak memberi pengaruh terhadap densitas akhir. Unsur Mg, Fe dan Si di dalam paduan AG3NE sebagian terlarut di dalam Al dan 
sebagian membentuk senyawa/fasa kedua. Demikian pula unsur $\mathrm{Mg}$ dan $\mathrm{Si}$ di dalam paduan AlMgSi juga sebagian larut di dalam Al dan sebagian membentuk senyawa/fasa kedua. Oleh karena unsur-unsur pemadu tersebut sebagian larut dan sebagian membentuk fasa kedua sehingga pada pengukuran densitas yang terukur adalah densitas matrik Al. Selain itu, unsur pemadu yang ditambahkan keduanya adalah sama yaitu $\mathrm{Mg}$ dan Si dan hanya berbeda Fe pada AG3NE dengan jumlah kecil.

Tabel 4. Densitas paduan AG3NE

\begin{tabular}{cccc}
\hline Nama sampel & Berat sampel $(\mathrm{g})$ & Rerata volume $(\mathrm{cc})$ & Rerata densitas $(\mathrm{g} / \mathrm{cc})$ \\
\hline Paduan AG3NE & 2,5315 & $(0,9413 \pm 0,0005)$ & $(2,6893 \pm 0,0013)$ \\
Paduan AIMgSi & 4,8238 & $(1,7926 \pm 0,0005)$ & $(2,6910 \pm 0,0283)$ \\
\hline
\end{tabular}

\section{f. Laju korosi}

Hasil uji korosi menggunakan alat potensiostat dan pencacahan dengan metode polarization resistance (Polres) dan Tafel scan diperoleh data laju korosi seperti pada Tabel 5 dan Gambar 11 hingga 13. Tabel 5 dan Gambar 11 hingga 13 menunjukkan bahwa ketahanan korosi paduan AG3NE sebesar 0,2102 mpy dengan metode Polres sedangkan dengan menggunakan metode Tafel ketahanan korosi sebesar 0,1577 mpy. Hasil yang diperoleh dari kedua metoda hampir sama. Apabila dibandingkan dengan paduan AIMgSi yang mempunyai ketahanan korosi sebesar 0,1076 mpy, terlihat bahwa ketahanan korosi paduan AG3NE lebih baik. Hal ini disebabkan karena pada paduan AG3NE terdapat senyawa $\mathrm{FeSiAl}_{5}$ sedangkan AlMgSi terdapat senyawa $\mathrm{Mg}_{2} \mathrm{Si}$ [11]. Kedua senyawa $\mathrm{FeSiAl}_{5}$ dan $\mathrm{Mg}_{2} \mathrm{Si}$ mempunyai perbedaan potensial dengan matriks Al masing-masing sebesar $-0,04$ dan -2,38[12]. Dari perbedaan potensialnya dengan matriks Al maka $\mathrm{FeSiAl}_{5}$ mempunyai perbedaan potensial yang lebih rendah sehingga paduan AG3NE mempunyai ketahanan korosi yang lebih baik.

Tabel 5. Data uji laju korosi paduan AG3NE

\begin{tabular}{|c|c|c|c|c|c|c|c|}
\hline \multirow[b]{2}{*}{ Media } & \multicolumn{3}{|c|}{ Metode Polres } & \multicolumn{4}{|c|}{ Metode Tafel } \\
\hline & $\begin{array}{c}\mathrm{Rp} \\
\text { (kOhms) }\end{array}$ & $\begin{array}{c}\text { Icorr } \\
\text { (Ampere) }\end{array}$ & $\begin{array}{c}\text { CR } \\
\text { (mpy) }\end{array}$ & $\begin{array}{c}\beta a \\
\text { (V/decade) }\end{array}$ & $\begin{array}{c}\beta c \\
\text { (V/decade) }\end{array}$ & $\begin{array}{c}\text { Icorr } \\
\text { (Ampere) }\end{array}$ & $\begin{array}{c}\text { CR } \\
\text { (mpy) }\end{array}$ \\
\hline Air & 66,55 & $7,054 \times 10^{-1}$ & 0,1202 & 0,2102 & 0,02226 & $9,26 \times 10^{-1}$ & 0,1577 \\
\hline
\end{tabular}

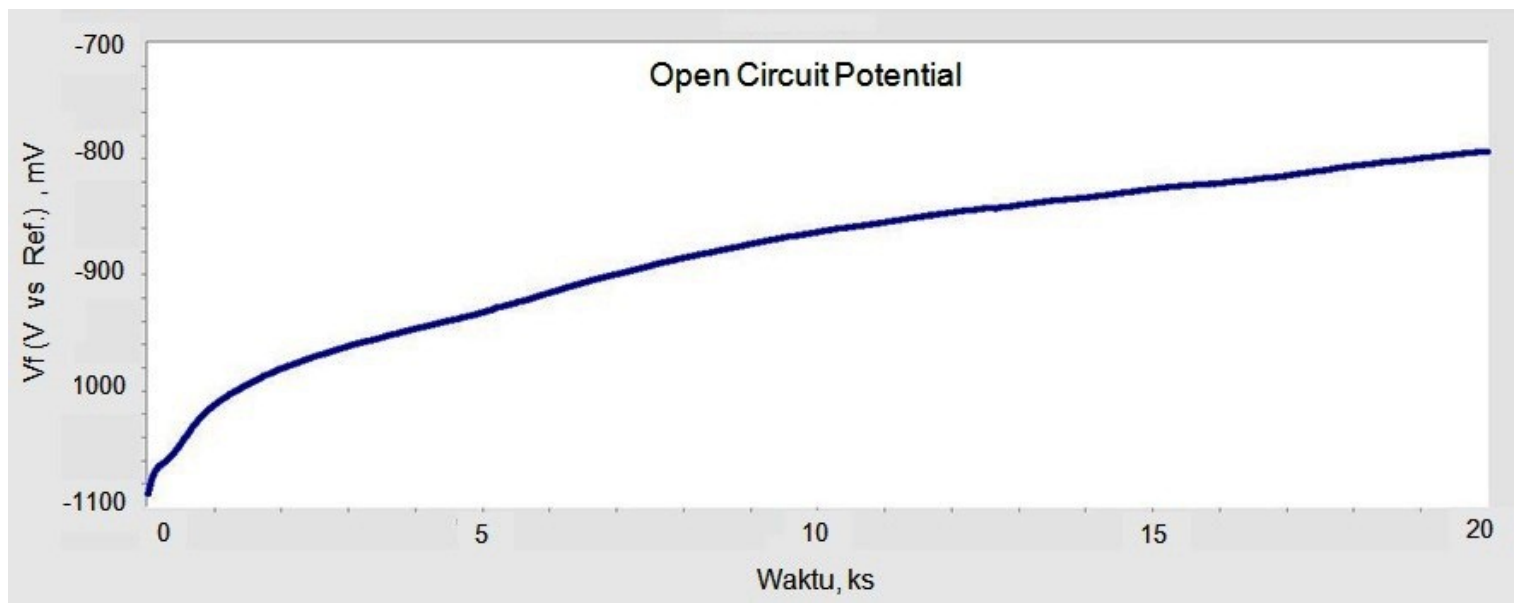

Gambar 11. Open circuit potential paduan AG3NE 


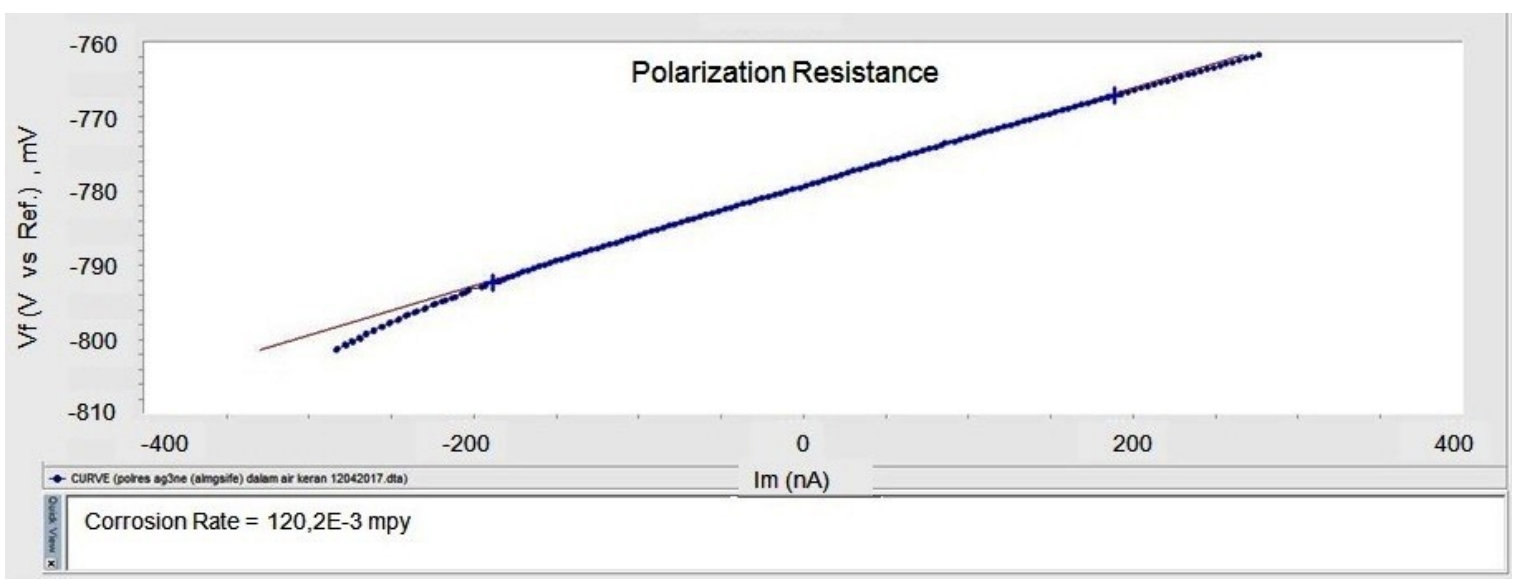

Gambar 12. Polarization resistance paduan AG3NE

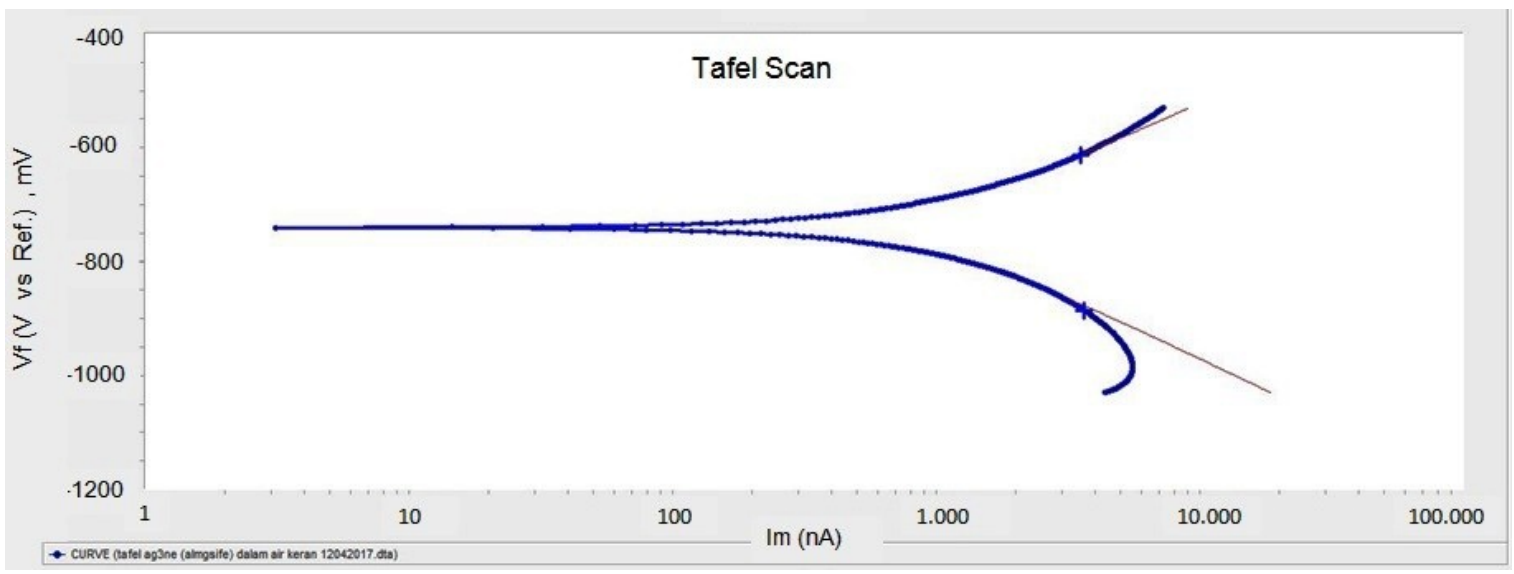

Gambar 13. Tafel scan paduan AG3NE

\section{SIMPULAN}

Paduan AG3NE mempunyai komposisi kimia yang terdiri dari $\mathrm{Al}=96,110 \% ; \mathrm{Fe}=0,188 \% ; \mathrm{Mg}=2,333 \%$ dan $\mathrm{Si}=0,355 \%$. Paduan AG3NE yang diperoleh melalui pendinginan cepat mempunyai kekerasan 153,33 HV, dimana kekerasan tersebut lebih tinggi dibandingkan AG3NE yang diperoleh melalui pendinginan lambat dengan kekerasan sebesar $72,22 \mathrm{HV}$. Kekerasan paduan AG3NE yang dihomogenisasi pada temperatur $500^{\circ} \mathrm{C}$ dan dirol pada tingkat reduksi yang bervariasi menunjukkan bahwa pada reduksi pengerolan yang semakin tinggi kekerasan paduan hanya meturun sedikit. Hasil pemeriksaan mikrostruktur paduan AG3NE tanpa dihomogenisasi mempunyai bentuk butir pipih dengan diameter butir rata-rata $0,02 \mathrm{~mm}$ sedangkan untuk paduan AG3NE yang dihomogenisasi pada temperatur $500^{\circ} \mathrm{C}$ selama 1 jam, 2 jam, 3 jam dan 4 jam mempunyai butir yang semakin besar dengan diameter butir rata-rata sebesar $0,01 \mathrm{~mm}, 0,02 \mathrm{~mm}, 0,03 \mathrm{~mm}$ dan $0,04 \mathrm{~mm}$. Hasil pengujian fasa menggunakan metode difraksi sinar-X (XRD) menunjukkan paduan AG3NE terdiri dari fasa Al (ó) dan $\mathrm{FeSiAl}_{5}$. Hasil pengujian densitas AG3NE menunjukkan bahwa nilai densitas AG3NE hampir sama dengan densitas AIMgSi yakni masing-maisng sebesar $2,6893 \mathrm{~g} / \mathrm{cm}^{3}$ dan $2,6910 \mathrm{~g} / \mathrm{cm}^{3}$. Sementara itu, hasil pengujian ketahanan korosi menunjukkan bahwa ketahanan korosi AG3NE sebesar sebesar 0,2102 mpy. Hasil tersebut lebih baik bila dibandingkan dengan ketahanan korosi paduan AIMgSi yang mempunyai ketahanan korosi sebesar 0,107579 mpy. Dari hasil karakterisasi paduan AG3NE 
diketahui bahwa temperatur dan waktu homogenisasi berpengaruh terhadap kekerasan mikro, mikrostruktur, fasa, densitas dan korosi, namun perubahan karakter tersebut tidak berpengaruh terhadap fungsi paduan AG3NE sebagai kelongsong bahan bakar reaktor riset.

\section{UCAPAN TERIMA KASIH}

Ucapan terima kasih penulis sampaikan pada Kepala Pusat Teknologi Bahan Bakar Nuklir dan Kepala Bidang Fabrikasi Bahan Bakar Nuklir yang telah memfasilitasi penelitian ini serta teman-teman BFBBN terutama Bapak Yatno DAS, Bapak Slamet Pribadi, Ibu Mujinem dan Ibu Asminar yang telah banyak membantu sehingga penelitian dan penulisan makalah bisa terlaksana dengan baik.

\section{DAFTAR PUSTAKA}

[1] M.H Al Hasa, "Karakterisasi sifat mekanik dan mikrostruktur paduan intermetalik AIFeNi sebagai bahan kelongsong bahan bakar," Jurnal Teknologi Bahan Bakar Nuklir, vol. 3 no. 2, 2007.

[2] E. Nurlia, S. Purwadaria, E.A. Basuki, "Evaluasi pengaruh perlakuan panas RRA terhadap kekuatan mekanik dan peningkatan ketahanan SCC paduan Aluminium 7075," Prosiding Seminar Material Metalurgi, 2012, LIPI.

[3] A.B.Ginting, "Analisis termal paduan AIMgSi untuk kelongsong bahan bakar $\mathrm{U}_{3} \mathrm{Si}_{2}-\mathrm{Al}$ densitas tinggi,"Jurnal IImiah Daur Bahan Bakar Nuklir Urania, vol. 16, no 2, 2010.

[4] S. Menargues, E. Martín, M.T. Baile, J.A. Picas, "New short T6 heat treatments for aluminium silicon alloy obtained by semisolid forming. Journal of Materials Science \& Engineering, vol. 621, pp.236-242, 2015.

[5] M.H. Al Hasa, "Formasi fasa dan mikrostruktur bahan struktur paduan aluminium feronikel hasil proses sintesis," Prosiding PPI-PDIPTN 2007, PTAPB, Yogyakarta.

[6] A.B.Ginting, Supardjo, Yanlinastuti, D. Anggraini, Boybul, "Karakterisasi paduan AIMgSi untuk kelongsong bahan bakar $\mathrm{U}_{3} \mathrm{Si}_{2} / \mathrm{Al}$ dengan densitas uranium 5,2 gU/cm ${ }^{3}$," Jurnal IImiah Daur Bahan Bakar Nuklir Urania, vol. 24, no. 1, hal. 27-38, 2018.

[7] S.C. Ram, K. Chattopadhyay, I. Chakrabarty, "High temperature Tensile properties of centrifugally cast in-situ $\mathrm{AlMg}_{2} \mathrm{Si}$ functionally graded composites for automotive cylinder block liners," Journal of Alloys and Compounds, vol. 724, pp. 84-97, 2017.

[8] M.F. Ibrahim, S.A. Alkahtani, K.A. Abuhasel, F.H.Samuel, "Microstructural characterization of beryllium treated AISi Alloys," Proceeding of Advances in Materials Science and Engineering, 2015, pp.1-0.

[9] M. Syahid, B.T. Sofyan, S.G. Basuki, B. Adam, "Characterization of Al-7Si-Mg$\mathrm{Cu}$ turbine impeller produced by investment casting," Proceeding of Advanced Materials Research, 2013, vol. 789, pp. 324-329.

[10] L. Sweet, S.M. Zhu, S.X. Gao, J.A. Taylor, M.A. Easton, "The effect of iron content on the iron containing intermetallic phases in a cast 6060 aluminium alloy," Mettalurgical and Materials Transaction, vol. 42 A, 2011.

[11] A. Dobkowska, B. Adamczyk-Cieślak, J. Mizera, K.J. Kurzydłowski, A. Kiełbus, "The comparison of the microstructure and corrosion resistance of sand cast aluminum alloys. Proceeding of Arch. Metall. Mater., vol. 61, no 1, pp. 209-212.

[12] A. Kruglova,"Influence of Microstructure on Mechanical Properties and Damage Characteristics of Al-Si Alloys," Disertation of Doctor at Saarlandes University, 2017. 